\title{
Sistemas de preparo do solo e de semeadura no rendimento de grãos de soja em área de várzea
}

Soil tillage systems and seeding on grain yield of soybean in lowland area

\author{
Gerson Meneghetti Sarzi Sartori ${ }^{\mathrm{I}}$ Enio Marchesan ${ }^{\mathrm{I}}$ Ricardo De David $^{\mathrm{I}}$ Gabriel Donato $^{\mathrm{I}}$ \\ Lucas Lopes Coelho ${ }^{I}$ Núbia Pentiado Aires ${ }^{I}$ Bruno Behenck Aramburu ${ }^{I}$
}

RESUMO

A presença de camada compactada próxima à superficie do solo e a variabilidade das propriedades químicas do solo podem afetar o rendimento de grão de soja. Com o trabalho, objetivou-se avaliar a influência de sistemas de preparo do solo e de semeadura e de locais de cultivo (áreas de corte e aterro) no rendimento dessa cultura. $O$ experimento foi realizado na área experimental de várzea da Universidade Federal de Santa Maria, nas safras 2013/14 e 2014/15. O delineamento foi blocos ao acaso, com quatro repetições. Os tratamentos foram arranjados em parcelas subdivididas. As parcelas principais foram: área de corte (A1) e área de aterro (A2). As subparcelas foram os tipos de preparo do solo e de semeadura: com escarificação do solo e semeadura utilizando disco duplo na semeadora (D1); sem escarificação do solo e semeadura utilizando haste sulcadora na semeadora (D2); sem escarificação do solo e semeadura utilizando disco duplo na semeadora (D3). A cultivar utilizada foi a BMX Tornado. O tratamento com escarificação e haste sulcadora reduziu a resistência do solo à penetração e proporcionou maior teor de Mg e S no tecido foliar na safra 2013/14; e de N, P, K, Ca, Mg e S, em 2014/15. Esse tipo de preparo de solo possibilita maior rendimento de grão de soja sem diferenças entre as áreas de corte e de aterro.

Palavras-chave: compactação do solo, área de aterro, haste sulcadora, escarificação do solo.

\section{ABSTRACT}

The presence of soil compaction next to the soil surface and the variability of soil chemical properties can affect the soybean yield. The objective was to evaluate the influence of soil tillage systems and seeding on two sites area (cut and fill) on soybean grain yield. The experiment was conducted in lowland area of the Federal University of Santa Maria in 2013/14 and 2014/15 harvest. The design was a randomized block with four replications, with split plots. The main plots: the cuts area (A1) and fills area
(A2). The subplots were tillage systems and seeding: deep tillage (D1); planter using shank (D2); planter using double disc (D3). The cultivar used was BMX Tornado and sowing on November 26 and 14 from 2013 and 2014, respectively. The treatment with deep tillage and planter using shank reduced the penetration resistance and provided greater content of $M g$ and $S$ on 2013/14 and N, P, $\mathrm{K}, \mathrm{Ca}, \mathrm{Mg}$ e S on 2014/15. Those systems enables higher soybean yield, without difference between cut and fill area.

Key words: soil compaction, fill area, shank, deep tillage.

\section{INTRODUÇÃO}

O cultivo de soja em rotação com o arroz irrigado nas áreas de várzea teve um avanço significativo nas últimas safras, ultrapassando a 300 mil hectares na safra de 2014/15 (IRGA, 2014). No entanto, devido a alguns atributos físicos naturais dos solos nessas áreas e relevo predominantemente plano, o cultivo da soja pode ser prejudicado.

Destaca-se o hidromorfismo (BORGES et al., 2004) que, somado ao relevo plano, dificulta a drenagem de água (MARCHEZAN et al., 2002). Com isso, principalmente em anos de El Ninõ, em função da dificuldade de drenagem, o crescimento e desenvolvimento de culturas ditas de sequeiro como a soja pode ser prejudicado nessas áreas. Além disso, em função das operações de preparo da área para o cultivo do arroz, tem-se verificado a presença de uma camada compactada próxima à superfície do solo, causando aumento da densidade

\footnotetext{
IDepartamento de Fitotecnia, Centro de Ciências Rurais (CCR), Universidade Federal de Santa Maria (UFSM), 97105-900, Santa Maria, RS, Brasil. E-mail: gersonmss@yahoo.com.br. "Autor para correspondência.
} 
do solo e redução da macroporosidade e porosidade total (MENTGES et al., 2013). Com isso, ocorre aumento da resistência do solo à penetração (SPERA et al., 2012), modificando a habilidade das raízes em extrair água e nutrientes (CALONEGO et al., 2011), podendo, com isso, interferir no rendimento de grãos das plantas. Além disso, muitas áreas de várzeas são sistematizadas, e esse processo causa desuniformidade nos atributos físico-químicos do solo entre as áreas de corte e aterro (MARCHEZAN et al., 2001). De acordo com REICHERT et al. (2008), a heterogeneidade dos atributos do solo afeta diferenciadamente o desenvolvimento e a produtividade das culturas agrícolas.

Dessa forma, com a presença de uma camada compactada próximo à superfície do solo, somado à desuniformidade que pode ocorrer dos atributos físico-químicos do solo em função da sistematização das áreas de várzeas, o cultivo da soja em rotação com o arroz irrigado pode ser prejudicado. Assim, é fundamental identificar alternativas como sistemas de preparo do solo e de semeadura que proporcionem maior rendimento de grãos de soja em áreas de várzea, além de identificar se há diferenças no rendimento de grãos entre as áreas de corte e aterro, para auxiliar no manejo da cultura nessas áreas. Em função disso, o trabalho teve por objetivo avaliar a influência de sistemas de preparo de solo, de semeadura e de locais (corte e aterro) sobre rendimento de grãos de soja em área de várzea sistematizada.

\section{MATERIAL E MÉTODOS}

O experimento foi realizado nas safras de 2013/14 e 2014/15 na área experimental de várzea sistematizada da Universidade Federal de Santa Maria (UFSM), em solo classificado como Planossolo Háplico Eutrófico arênico, pertencente à unidade de mapeamento Vacacaí (EMBRAPA, 2013). Na safra de 2013/14, o experimento foi realizado em área que na safra anterior havia a cultura da soja e, na safra de 2014/15, havia a cultura do arroz irrigado anteriormente à realização do experimento. Os valores dos seguintes atributos físicoquímicos do solo, aos 60 dias antes da semeadura, correspondiam a: argila $=25$ a $26 \% ; \mathrm{pH}_{\text {água }}=5,4$ a 5,4 ; $\mathrm{P}=18$ a $15,3 \mathrm{mg} \mathrm{dm}^{-3} ; \mathrm{K}=60$ a $44 \mathrm{mg} \mathrm{dm}^{-3} ; \mathrm{Ca}=5,3 \mathrm{a}$ $8,3 \mathrm{cmol}_{\mathrm{c}} \mathrm{dm}^{-3} ; \mathrm{Mg}=2,4$ a $3,1 \mathrm{cmol}_{\mathrm{c}} \mathrm{dm}^{-3}$ e M.O. $=2,0$ a $2,0 \%$, nas safras 2013/14 e 2014/15, respectivamente. Esses resultados foram obtidos em análises no laboratório de análises de solo (LAS) da UFSM conforme metodologia de TEDESCO et al. (1995).

$$
\text { O delineamento experimental foi } o
$$
de blocos ao acaso, com quatro repetições. $\mathrm{O}$ arranjo dos fatores foi em parcelas subdivididas. A sistematização da área foi realizada há quinze anos, com profundidade de corte máxima de $30 \mathrm{~cm}$. A parcela principal foi composta pelos locais: área de corte (A1) e área de aterro (A2). As subparcelas foram os sistemas de preparo do solo e de semeadura: com escarificação do solo e semeadura utilizando disco duplo na semeadora (D1); sem escarificação do solo e semeadura utilizando haste sulcadora na semeadora (D2); sem escarificação do solo e semeadura utilizando disco duplo na semeadora (D3).

A escarificação do solo foi realizada aos 45 e 19 dias antes da semeadura, na safra de 2013/14 e 2014/15, respectivamente, na profundidade de $25 \mathrm{~cm}$. A profundidade de trabalho da haste sulcadora e do disco duplo desencontrado no solo foi aproximadamente de 18 e $10 \mathrm{~cm}$, respectivamente. A semeadura foi realizada no dia 7 e 14 de novembro de 2013 e 2014, respectivamente, utilizando uma semeadora adubadora pantográfica. Devido a uma precipitação pluvial de $245 \mathrm{~mm}$ distribuídos em quatro dias, iniciando aos dois dias após a semeadura, o experimento foi ressemeado no dia 26 de novembro de 2013 (safra 2013/14). A cultivar de soja utilizada foi a BMX Tornado, que possui hábito de crescimento indeterminado. Foram distribuídas 26 sementes por $\mathrm{m}^{-2}$. O espaçamento entre linhas foi de $0,5 \mathrm{~m}$.

A adubação de semeadura foi de $30 \mathrm{~kg} \mathrm{ha}^{-1}$ de nitrogênio (N), $60 \mathrm{~kg} \mathrm{ha}^{-1}$ de $\mathrm{P}_{2} \mathrm{O}_{5}$ e $60 \mathrm{~kg} \mathrm{ha}^{-1}$ de $\mathrm{K}_{2} \mathrm{O}$. Em função da ressemeadura, utilizaram-se mais $10 \mathrm{~kg}$ ha $^{-1}$ de N, 20kg ha- de $\mathrm{P}_{2} \mathrm{O}_{5}$ e $20 \mathrm{~kg} \mathrm{ha}^{-1}$ de $\mathrm{K}_{2} \mathrm{O}$ (safra 2013/14). Na safra de 2014/15, essa adubação foi de $13 \mathrm{~N}, 54 \mathrm{~kg} \mathrm{ha}^{-1}$ de $\mathrm{P}_{2} \mathrm{O}_{5}$ e $86 \mathrm{~kg} \mathrm{ha}^{-1}$ de $\mathrm{K}_{2} \mathrm{O}$. Optou-se pela utilização de $\mathrm{N}$ na semeadura, pois os alagamentos frequentes e a presença de camada compactada poderiam limitar o conteúdo de oxigênio do solo e, consequentemente, a nodulação. Além disso, não há informação suficiente na literatura sobre o uso ou não de fertilizantes nitrogenados na semeadura da cultura da soja para o ambiente de várzea. Os demais tratos culturais foram realizados conforme as recomendações técnicas para cultura (EMBRAPA, 2012).

Aos 10 dias antes da semeadura, realizouse avaliação da resistência do solo à penetração, para caracterizar a profundidade da camada compactada na área. Essa avaliação também foi realizada aos 2 e 15 dias após a semeadura, na linha de cultivo, visando identificar o efeito do rompimento de parte dessa camada, em cada sistema, nas safras de 2013/14 e 2014/15, respectivamente. Essa avaliação foi na profundidade de até $30 \mathrm{~cm}$, utilizando penetrômetro digital da marca Falcker, modelo PLG 1020. A densidade do solo e a porosidade foram realizadas 10 
dias antes da semeadura, na camada de $0-10$ e de 10 $20 \mathrm{~cm}$, conforme métodos descritos pela EMBRAPA (1997). A densidade do solo foi obtida pelo método do anel volumétrico. A porosidade total $(\mathrm{Pt})$ foi calculada a partir da densidade do solo (Ds) e a macroporosidade foi calculada pela diferença entre a porosidade total e a microporosidade.

Avaliaram-se os seguintes atributos das amostras de solo: $\mathrm{pH}_{\text {água }}$; cálcio $(\mathrm{Ca})$; magnésio $(\mathrm{Mg})$; Sat Bases; matéria orgânica (M.O.); enxofre (S); fósforo $(\mathrm{P})$; CTC pH7; potássio $(\mathrm{K})$; cobre $(\mathrm{Cu})$; Zinco (Zn) e boro (B) conforme TEDESCO et al. (1995). As amostras foram coletadas nas áreas de corte e aterro, no estádio R2 da soja, segundo escala de FEHR \& CAVINESS (1977). As coletas foram realizadas com pá de corte, na camada de $0-20 \mathrm{~cm}$ e na entrelinha de semeadura. Para amostragem do solo, foram utilizadas 12 repetições em cada local, na safra de 2013/14 e quatro repetições, na safra de 2014/15. Nas plantas, avaliaram-se os teores dos nutrientes N; P; K; Ca; Mg; e S no estádio R2, segundo escala de FERHR \& CAVINESS (1977). Coletou-se o terceiro trifólio completamente expandindo, da haste principal, do ápice para a base, de 15 plantas consecutivas em cada parcela. As amostras foram encaminhadas para o laboratório de Ecologia Florestal da UFSM para análise dos nutrientes, conforme metodologia de TEDESCO et al. (1995) e MIYAZAWA et al. (1999).

Os parâmetros avaliados foram submetidos ao teste das pressuposições do modelo matemático (normalidade e homogeneidade das variâncias). A análise da variância dos dados dos experimentos foi realizada com teste $\mathrm{F}$. As médias dos locais (área de corte e aterro), quando significativas, foram comparadas pelo teste $\mathrm{t}$ bilateral, a $5 \%$ de probabilidade de erro; e as médias dos sistemas de preparo do solo e de semeadura foram comparadas pelo teste Tukey, utilizando esse mesmo nível de probabilidade de erro.

\section{RESULTADOS E DISCUSSÃO}

O solo da área em que foi realizado o experimento tinha valores limitantes $(<10 \%)$ de macroporos e elevada relação de micromacroporos, até os $20 \mathrm{~cm}$ de profundidade (Tabela 1). Além disso, os valores de densidade do solo eram elevados (superior a $1,65 \mathrm{~g} \mathrm{~cm}^{-3}$ ), principalmente na área de corte e na camada de $10-20 \mathrm{~cm}$ nas safras de $2013 / 14$ e $2014 / 15$.

As áreas de corte e de aterro da camada de $8-17 \mathrm{~cm}$ na safra de 2013/14 (Figuras 1A, B) e dos $5-17 \mathrm{~cm}$ da safra de 2014/15 (Figuras 1C, D) tiveram valores de resistência do solo à penetração maior que
2,0MPa. $\mathrm{Na}$ área de corte, registraram-se valores médios de 0,8 e $0,3 \mathrm{MPa}$ superiores à área de aterro, na safra de 2013/14 e 2014/15, respectivamente, nessa camada de solo. Isso pode estar relacionado aos valores mais acentuados de densidade do solo, pois ORTIGARA et al. (2014) encontraram aumento exponencial e positivo da resistência à penetração, com o aumento dos valores de densidade do solo.

Os sistemas de preparo do solo e de semeadura, em ambos os locais e safras, responderam de forma diferenciada quanto à redução da resistência do solo à penetração na linha de semeadura. O sistema com escarificação do solo utilizando o disco duplo no momento da semeadura e a semeadura utilizando haste sulcadora reduziram os valores de resistência do solo à penetração a valores menores que $1,5 \mathrm{MPa}$, até os $15 \mathrm{~cm}$ de profundidade. Já a semeadura com disco duplo, em área sem escarificação do solo, proporcionou menor redução da resistência, mantendo a camada compactada na linha de semeadura, visto que a resistência à penetração tem sido amplamente utilizada em avaliações do estado de compactação dos solos (FLORES et al., 2007). De acordo com TAYLOR et al. (1966), valores de resistência à penetração do solo maior de $2,0 \mathrm{MPa}$ são considerados limitantes ao crescimento e desenvolvimento do sistema radicular das plantas. $\mathrm{O}$ menor efeito do disco duplo está associado a pouca ação em profundidade desse sistema no solo, que foi de aproximadamente $10 \mathrm{~cm}$, em comparação aos 25 e $18 \mathrm{~cm}$ para a escarificação e haste sulcadora na semeadora, respectivamente.

De acordo com os resultados dos atributos físico-químicos do solo quando as plantas estavam em R2 (Tabela 1), a faixa de interpretação dos teores de $\mathrm{Cu}, \mathrm{Zn}, \mathrm{B}, \mathrm{Ca}, \mathrm{Mg}$ e $\mathrm{S}$ é alto, e médio, para o $\mathrm{K}$, em ambas as safras e locais, com exceção do B, que estava médio na safra 2013/14. Os teores de P do solo, nas safras 2013/14 e 2014/15, estavam muito alto e médio, respectivamente. De maneira geral, os teores dos nutrientes $\mathrm{Ca}, \mathrm{Mg}, \mathrm{S}, \mathrm{P}, \mathrm{K}, \mathrm{Cu}$ e $\mathrm{Zn}$ (safra 2013/14), B e P (safra 2014/15) da área de aterro foram superiores, em relação à área de corte. Segundo MARCHEZAN et al. (2001), o processo de sistematização causa desuniformidade nas características físico-químicas do solo entre as áreas de corte e aterro, principalmente nos primeiros anos de cultivo nessas áreas.

Em relação aos resultados apresentados na tabela 2, não houve interação entre os fatores de estudo. A análise dos teores de macrocronutrientes no tecido foliar das plantas em R2, na safra de 2013/14, indicou maior teor de $\mathrm{Ca}$ na área de aterro e de $\mathrm{N}$ 
Tabela 1 - Densidade do solo (Ds), porosidade total (Pt), microporos (Mi), macroporos (Ma) e relação Mi/Ma, na área de corte (AC) e aterro (AA), em duas camadas do solo e atributos químicos do solo da área de corte e de aterro, no estádio R2, nas safras de 2013/14 e 2014/15. Santa Maria, RS. 2015.

\begin{tabular}{|c|c|c|c|c|c|c|c|}
\hline Local & Camada $(\mathrm{cm})$ & Ds $\left(\mathrm{g} \mathrm{cm}^{-3}\right)$ & $\mathrm{Pt}(\%)$ & $\operatorname{Mi}(\%)$ & $\mathrm{Ma}(\%)$ & \multicolumn{2}{|l|}{$\mathrm{Mi} / \mathrm{Ma}$} \\
\hline ------ & --------- & & 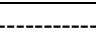 & 013/14---- & ------. & ----- & \\
\hline \multirow{2}{*}{$\mathrm{AC}$} & $0-10$ & 1,52 & 48 & 39 & 9 & $4: 1$ & \\
\hline & $10-20$ & 1,67 & 43 & 35 & 8 & $5: 1$ & \\
\hline \multirow{2}{*}{$\mathrm{AA}$} & $0-10$ & 1,40 & 52 & 41 & 11 & $4: 1$ & \\
\hline & $10-20$ & 1,66 & 43 & 35 & 9 & $4: 1$ & \\
\hline & & & & 014/15----. & 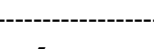 & -------. & -----------. \\
\hline \multirow{2}{*}{$\mathrm{AC}$} & $0-10$ & 1,61 & 39 & 34 & 5 & $7: 1$ & \\
\hline & $10-20$ & 1,70 & 37 & 32 & 5 & $5: 1$ & \\
\hline \multirow{2}{*}{$\mathrm{AA}$} & $0-10$ & 1,56 & 37 & 30 & 6 & $5: 1$ & \\
\hline & $10-20$ & 1,62 & 33 & 31 & 7 & $4: 1$ & \\
\hline \multirow{2}{*}{ Local } & \multirow{2}{*}{ pH água 1:1 } & \multirow{2}{*}{\multicolumn{2}{|c|}{$\mathrm{cmol}_{\mathrm{c}} \mathrm{dm}^{-3}$}} & Sat Al & Sat Bases & MO & $\mathrm{S}$ \\
\hline & & & & & \multicolumn{2}{|l|}{$\%$} & $\mathrm{mg} \mathrm{dm}^{-3}$ \\
\hline $\mathrm{AC}$ & 5,3 & 8,1 & 3,5 & 1,7 & 79,1 & 1,4 & 10,5 \\
\hline AA & 5,1 & 8,5 & 3,6 & 2,0 & 76,3 & 1,8 & 18,2 \\
\hline $\mathrm{AC}$ & 5,8 & 8,8 & 3,9 & $\begin{array}{c}014 / 15--- \\
0,0\end{array}$ & 81,9 & 1,5 & 23 \\
\hline AA & 5,3 & 6,6 & 2,8 & 3,0 & 63,7 & 1,8 & 10 \\
\hline Local & $\mathrm{P} \mathrm{mg} \mathrm{dm}{ }^{-3}$ & $\begin{array}{c}\text { CTCpH7 } \mathrm{cmol}_{\mathrm{c}} \\
\mathrm{dm}^{-3}\end{array}$ & $\mathrm{~K}$ & \multicolumn{2}{|c|}{$\mathrm{mg} \mathrm{dm}^{-3}$} & B & \\
\hline $\mathrm{AC}$ & 11,1 & 14,8 & 55,0 & 1,3 & 0,6 & 0,2 & \\
\hline AA & 27,8 & 16,1 & 70,0 & 1,4 & 1,1 & 0,2 & \\
\hline $\mathrm{AC}$ & 6,0 & 15,7 & 76,0 & 1,8 & 1,1 & 0,4 & \\
\hline AA & 10,9 & 15,1 & 72,0 & 1,7 & 1,0 & 0,5 & \\
\hline
\end{tabular}

na área de corte. Entre os sistemas de preparo e de semeadura, verificaram-se maiores teores de $\mathrm{Mg}$ e de $\mathrm{S}$ nos sistemas com haste sulcadora e com escarificação do solo. Na safra de 2014/15, verificou-se maior teor de $\mathrm{Ca}$ e de $\mathrm{Mg}$ no tecido foliar da área de corte, em relação à área de aterro, não ocorrendo diferenças com os demais macronutrientes. A análise foliar indicou maior teor dos macronutrientes no sistema com escarificação do solo, seguido com semeadura utilizando haste sulcadora, que proporcionou maior teor de N, Ca e de Mg, em comparação ao disco duplo.

$\mathrm{O}$ menor teor de alguns nutrientes verificado no tecido foliar da área de aterro pode estar associado ao efeito de diluição, em função da maior massa seca das plantas nesse local que foi 21,3 e 17,0mg planta-1 ${ }^{-1}$ em comparação as das área de corte, que foi de 20,5 e $16,7 \mathrm{mg}$ planta $^{-1}$, nas safras 2013/14 e 2014/15, respectivamente (resultados não apresentados).
A maior redução da camada compactada do solo na linha de semeadura para o sistema com escarificação e semeadura utilizando haste sulcadora, em comparação ao disco duplo, como indicam os resultados de resistência à penetração, podem explicar o maior teor de macronutrientes do tecido foliar dos dois primeiros sistemas. DRESCHER et al. (2011), avaliando efeito do disco duplo e da haste sulcadora, verificaram que esse último é eficiente em aumentar a macroporosidade e diminuir a microporosidade e a densidade do solo, o que pode explicar os resultados encontrados. Em trabalho realizado por SOUZA et al. (2012), o aumento da compactação do solo reduziu o acúmulo de N, P, K, Ca, Mg e de S das plantas de soja. Com o aumento da compactação, ocorre aumento da resistência mecânica ao crescimento das raízes, limitação da aeração e da disponibilidade de água e nutrientes (GOEDERT et al., 2002). 


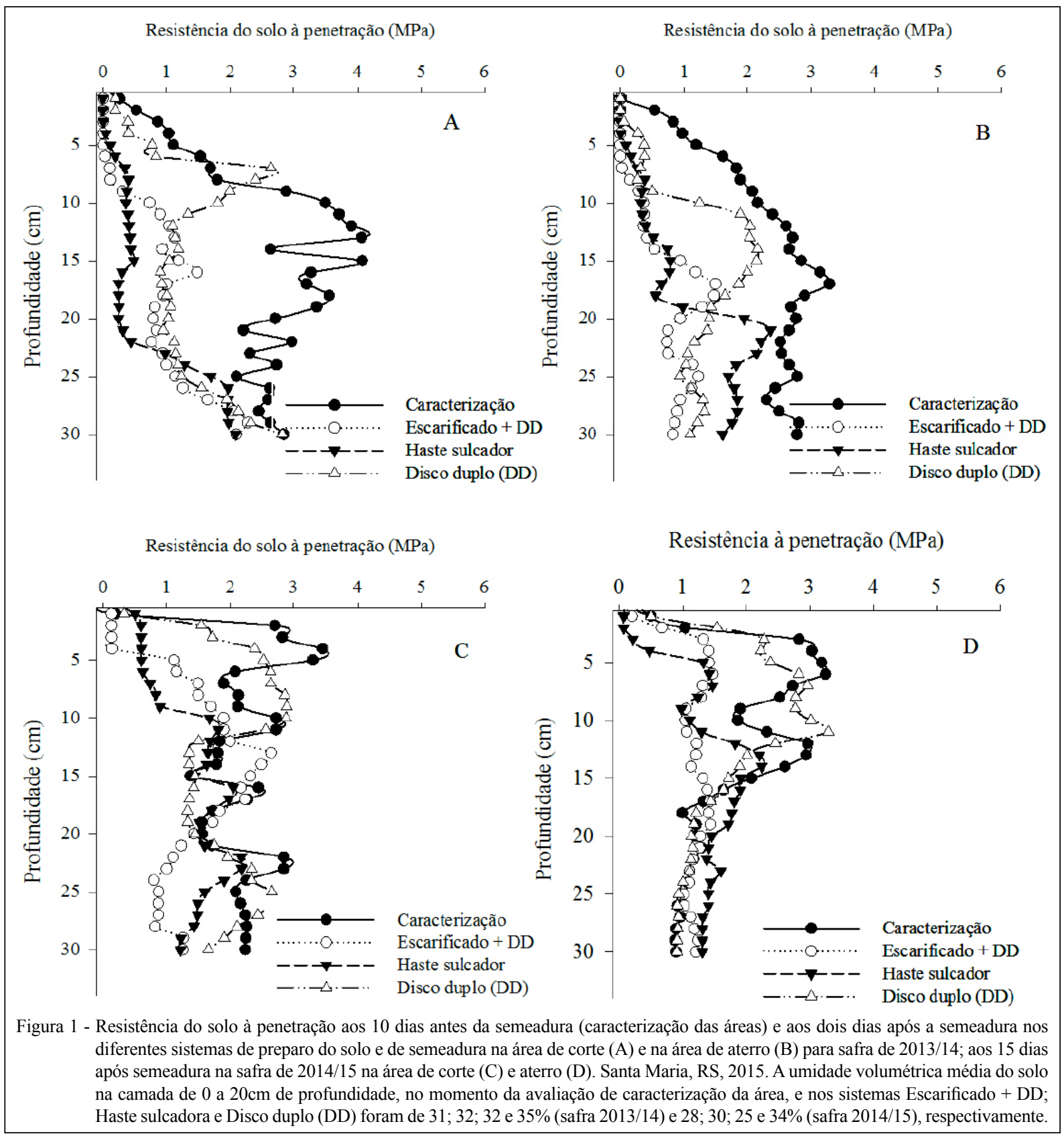

$\mathrm{Na}$ safra 2013/14, os teores de macronutrientes das plantas no estádio R2 são adequados para o desenvolvimento das plantas de soja (CQFSRS/SC, 2004). No entanto, na safra 2014/15, somente o teor de $\mathrm{K}$ do sistema com escarificação e de $\mathrm{Ca}$ e de $\mathrm{Mg}$, para os três sistemas, foram adequados.

Apesar da área de aterro, de forma geral, ser caracterizada por melhor fertilidade química, isso não se refletiu no rendimento de grão nas duas safras avaliadas. Uma hipótese para isso é a distribuição regular das chuvas que, associado à adubação realizada para o nível de rendimento obtido, atendeu às necessidades da planta em ambas as áreas. Os sistemas com escarificação do solo e haste sulcadora proporcionaram maior rendimento de grãos em comparação ao disco duplo em área sem escarificação do solo. Esses sistemas tiveram rendimento de 9 e $12 \%$, respectivamente, superior ao disco duplo (safra 2013/14) e 10 e $22 \%$, respectivamente, superior ao disco duplo (safra 2014/15). Isso está relacionado à maior redução da resistência à penetração do solo por esses sistemas

Ciência Rural, v.46, n.3, mar, 2016. 
Tabela 2 - Teor de macronutrientes do tecido foliar das plantas de soja no estádio R2 e rendimento de grão, em função dos sistemas de preparo do solo e de semeadura na área de corte (AC) e aterro (AA), nas safras de 2013/14 e 2014/15. Santa Maria, RS. 2015.

\begin{tabular}{|c|c|c|c|c|c|c|}
\hline \multirow{2}{*}{ Sistemas $^{1}$} & \multicolumn{6}{|c|}{--Macronutrientes $\left(\mathrm{g} \mathrm{kg}^{-1}\right)$ - } \\
\hline & $\mathrm{N}$ & $\mathrm{P}$ & $\mathrm{K}$ & $\mathrm{Ca}$ & $\mathrm{Mg}$ & $\mathrm{S}$ \\
\hline \multicolumn{7}{|c|}{ 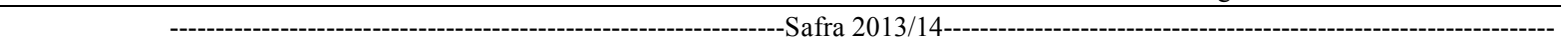 } \\
\hline DD & $49,19^{\mathrm{ns}}$ & $3,62^{\mathrm{ns}}$ & $19,87^{\mathrm{ns}}$ & $9,14^{\mathrm{ns}}$ & $5,39 \mathrm{~b}^{*}$ & $2,53 \mathrm{~b}$ \\
\hline HS & 55,33 & 4,07 & 16,88 & 9,44 & $5,86 \mathrm{a}$ & $2,85 \mathrm{ab}$ \\
\hline $\mathrm{E}+\mathrm{DD}$ & 52,75 & 3,87 & 21,04 & 9,27 & $5,88 \mathrm{a}$ & $2,92 \mathrm{a}$ \\
\hline \multicolumn{7}{|l|}{ Local } \\
\hline $\mathrm{AC}$ & $55,79^{* *}$ & $3,87^{\text {ns }}$ & $18,08^{\mathrm{ns}}$ & $9,08^{* *}$ & $5,56^{\mathrm{ns}}$ & $2,79^{\mathrm{ns}}$ \\
\hline $\mathrm{AA}$ & 49,05 & 3,80 & 20,44 & 9,48 & 5,86 & 2,73 \\
\hline Média & 52,42 & 3,84 & 19,26 & 9,28 & 5,71 & 2,76 \\
\hline $\mathrm{CV} \%$ & 10,31 & 9,97 & 19,43 & 4,64 & 7,62 & 8,57 \\
\hline \multicolumn{7}{|c|}{-----Safra 2014/15---- } \\
\hline DD & $31,81 \mathrm{c}$ & $1,84 \mathrm{~b}$ & $15,01 \mathrm{ab}$ & $7,48 \mathrm{c}$ & $3,29 \mathrm{c}$ & $1,49 \mathrm{~b}$ \\
\hline HS & $33,95 \mathrm{~b}$ & $1,91 \mathrm{~b}$ & $12,66 \mathrm{~b}$ & $8,03 \mathrm{~b}$ & $3,48 \mathrm{~b}$ & $1,57 \mathrm{~b}$ \\
\hline $\mathrm{E}+\mathrm{DD}$ & 36,18 a & $2,26 \mathrm{a}$ & 18,06 a & $8,47 \mathrm{a}$ & $3,65 \mathrm{a}$ & $1,48 \mathrm{a}$ \\
\hline \multicolumn{7}{|l|}{ Local } \\
\hline $\mathrm{AC}$ & $34,09^{\mathrm{ns}}$ & $1,95^{\mathrm{ns}}$ & $14,98^{\mathrm{ns}}$ & $8,13^{* *}$ & $3,59^{* *}$ & $1,52^{\mathrm{ns}}$ \\
\hline AA & 33,87 & 2,06 & 15,51 & 7,85 & 3,36 & 1,50 \\
\hline Média & 33,98 & 2,00 & 15,24 & 7,99 & 3,47 & 1,51 \\
\hline $\mathrm{CV} \%$ & 3,9 & 5,51 & 14,04 & 2,75 & 2,19 & 2,12 \\
\hline Sistemas & \multicolumn{3}{|c|}{ Safra 2013/14 } & \multicolumn{2}{|r|}{ Safra 2014/15 } & \\
\hline \multicolumn{2}{|l|}{ DD } & $3980 \mathrm{~b}$ & & \multicolumn{3}{|c|}{$3754 \mathrm{c}$} \\
\hline \multicolumn{2}{|l|}{ HS } & 4451 a & & \multicolumn{3}{|c|}{$4111 b$} \\
\hline \multicolumn{2}{|l|}{$E+D D$} & $4350 \mathrm{a}$ & & \multicolumn{3}{|c|}{$4564 \mathrm{a}$} \\
\hline \multicolumn{7}{|l|}{ Local } \\
\hline $\mathrm{AC}$ & & $4146^{\mathrm{ns}}$ & & & $4083^{\mathrm{ns}}$ & \\
\hline $\mathrm{AA}$ & & 4375 & & & 4203 & \\
\hline Média & & 4260 & & & 4143 & \\
\hline CV\% & & 6,64 & & & 3,68 & \\
\hline
\end{tabular}

$\mathrm{DD}=$ Disco duplo; $\mathrm{HS}=$ Haste sulcadora $; \mathrm{E}+\mathrm{DD}=$ Escarificado + Disco duplo.

$\mathrm{AC}=$ Área de corte; $\mathrm{AA}=$ Área de aterro.

${ }^{1}$ Sistemas de preparo do solo e de semeadura.

${ }^{\text {ns }}$ ão significativo em nível $\mathrm{P}=0,05$ na coluna.

*Médias não seguidas da mesma letra minúscula na coluna diferem entre si pelo teste Tukey em nível de 5\% de probabilidade de erro.

${ }^{* *}$ Diferença significativa entre os locais pelo teste t bilateral em nível de $5 \%$ de probabilidade de erro.

na linha de semeadura, o que contribui para maior teor de macronutrientes do tecido foliar das plantas. Segundo DRESCHER et al. (2012), a compactação do solo afeta a disponibilidade de água e de nutrientes para as plantas, reduzindo a fotossíntese, o crescimento e o rendimento de grão da cultura. Contribuindo com o estudo, REICHERT et al. (2008) encontraram que $65 \%$ da variação na produtividade de grãos de soja é atribuída a atributos químicos do solo e físicos, como a resistência à penetração.

Para todos os sistemas, o rendimento de grãos foi elevado, devido à boa disponibilidade de água proporcionada pelas precipitações pluviais, que foi de $305 ; 98 ; 140 ; 123 ; 242 ;$ e $116 \mathrm{~mm}$ (safra $2013 / 14$ ) e $65 ; 323 ; 189 ; 89 ; 145$ e $131 \mathrm{~mm}$ (safra 2014/15) nos meses de novembro, dezembro, janeiro, fevereiro, março e abril, respectivamente. Isso contribuiu para que todas as práticas de manejo expressassem seu potencial de resposta, pois disponibilidade de água é fundamental para obtenção de elevado rendimento (MIAO et al., 2012). Assim, restrições físicas do solo, como a presença de uma camada compactada próxima à superfície do solo, interferem nos teores foliares de macronutrientes das plantas e no rendimento de grão de soja, em área de várzea. 


\section{CONCLUSÃO}

O sistema de preparo do solo com escarificação e a semeadura utilizando haste sulcadora na semeadora proporcionam maior rendimento de grão de soja, em área de várzea, que contém camada compactada próxima à superfície do solo. Não há diferenças entre áreas de corte e aterro, em sistematização realizada há quinze anos.

\section{AGRADECIMENTOS}

À Coordenação de Aperfeiçoamento de Pessoal de Nível Superior (CAPES), pela bolsa de doutorado do primeiro autor. Ao Conselho Nacional de Desenvolvimento Científico e Tecnológico $(\mathrm{CNPq})$, pela bolsa de produtividade em pesquisa para o segundo autor e bolsa de doutorado ao primeiro autor. À Fundação de Apoio à Pesquisa do Estado do Rio Grande do Sul (FAPERGS), pela bolsa de Iniciação Científica concedida ao terceiro autor.

\section{REFERÊNCIAS}

BORGES, J.R. etal. Resistênciaà penetração de umgleissolo submetido a sistemas de cultivo e culturas. Revista Brasileira de Agrociência, v.10, n.1, p.83-86, 2004. Disponível em: $<$ http://periodicos.ufpel.edu. br/ojs2/index.php/CAST/article/viewFile/681/678>. Acesso em: 18 out. 2014. doi: 10.18539/CAST.V10I1.681.

CALONEGO, J.C. et al. Desenvolvimento de plantas de cobertura em solo compactado. Bioscience Journal, v.27, n.2, p.289-296, 2011.

COMISSÃO DE QUÍMICA E FERTILIDADE DO SOLO (CQFSRS/SC). Manual de adubação e calagem para os Estados do Rio Grande do Sul e de Santa Catarina. 10.ed. Porto Alegre, SBCS - Núcleo Regional Sul/UFRGS, 2004. 400p.

DRESCHER, M.S. et al. Persistência do efeito de intervenções mecânicas para a descompactação de solos sob plantio direto. Revista Brasileira de Ciência do Solo, v.35, n.5, p.1713-1722, 2011 Disponível em: <http://www.scielo.br/pdf/rbcs/v35n5/a26v35n5.pdf >. Acesso em: 18 out. 2014. doi: 10.1590/s0100-06832011000500026.

DRESCHER, M.S. et al. Resistência à penetração e rendimento da soja após intervenção mecânica em latossolo vermelho sob plantio direto. Revista Brasileira de Ciência do Solo, v.36, n.6, p.1836-1844, 2012. Disponível em: <http://www.scielo.br/pdf/rbcs/v36n6/18.pdf > . Acesso em: 18 out. 2014. doi: 10.1590/S0100-06832012000600018.

EMPRESA BRASILEIRA DE PESQUISA AGROPECUÁRIA (EMBRAPA). Manual de métodos de análises de solo. Rio de Janeiro, 1997. 212p

EMPRESA BRASILEIRA DE PESQUISA AGROPECUÁRIA (EMBRAPA). Indicações técnicas para a cultura da soja no Rio Grande do Sul e em Santa Catarina, safras 2012/2013 e 2013/2014. In: REUNIÃO DE PESQUISA DE SOJA DA REGIÃO SUL, 39, 2012, Passo Fundo, RS. Anais... Passo Fundo: Embrapa Trigo, 2012. 142p.

EMPRESA BRASILEIRA DE PESQUISA AGROPECUÁRIA (EMBRAPA). Sistema Brasileiro de Classificação dos Solos 3.ed. Brasília, 2013. 353p.

FEHR, W.R.; CAVINESS, C.E. Stages of soybean development Ames: State University of Science and Technology, 1977. 11p. (Special report, 80).
FLORES, J.P.C. et al. Atributos físicos do solo e rendimento de soja em sistema plantio direto em integração lavoura-pecuária com diferentes pressões de pastejo. Revista Brasileira de Ciência do Solo, v.31, n.4, p.771-780, 2007. Disponível em: <http://www. scielo.br/pdf/rbcs/v31n4/a17v31n4.pdf>. Acesso em: 18 out. 2014. doi: 10.1590/S0100-06832007000400017.

GOEDERT, W.J. et al. Estado de compactação do solo em áreas cultivadas no sistema plantio direto. Pesquisa Agropecuária Brasileira, v.37, n.2, p.223-227, 2002. Disponível em: <http://www.scielo.br/scielo. php?script=sci_arttext\&pid=S0100-204X2002000200015>. Acesso em: 18 out. 2014 . doi: 10.1590/S0100-204X2002000200015.

IRGA (INSTITUTO RIO GRANDENSE DO ARROZ). Irga divulga estimativa da Safra 2014/2015. Disponível em: <http:/ www.irga.rs.gov.br/conteudo/4869/irga-divulga-estimativa-dasafra-2014/2015>. Acesso em: 08 maio 2015

MARCHEZAN, E. et al. Adubação foliar com micronutrientes em arroz irrigado, em área sistematizada. Ciência Rural, v.31, n.6, p.941-945, 2001. Disponível em: <http://www.scielo.br/scielo. php?pid $=$ S0103-84782001000600003\&script $=$ sci arttext $>$. Acesso em: 18 out. 2014. doi: 10.1590/S0103-84782001000600003.

MARCHEZAN, E et al. Produção animal em várzea sistematizada cultivada com forrageiras de estação fria submetidas a diferentes níveis de adubação. Ciência Rural, v.32, n.2, p.303-308, 2002. Disponível em: <http://www.scielo.br/scielo.php?script=sci artte $\mathrm{xt} \& \mathrm{pid}=\mathrm{S} 0103-84782002000200020>$. Acesso em: 18 out. $\overline{2} 014$. doi:10.1590/S0103-84782002000200020.

MENTGES, M.I. et al. Alterações estruturais e mecânicas de solo de várzea cultivado com arroz irrigado por inundação. Revista Brasileira de Ciência do solo, v.37, n.1, p. 221-231, 2013. Disponível em: <http://www.scielo.br/scielo.php?pid=S0100 $06832013000100023 \&$ script $=$ sci_abstract\&tlng $=\mathrm{pt}>$. Acesso em: 18 out. 2014. doi: 10.1590/S0100-06832013000100023.

MIAO, S. et al. Effects of short-term drought and flooding on soybean nodulation and yield at key nodulation stage under pot culture. Journal of Food, Agriculture \& Environment, v.10, n. 34, p.819-824, 2012.

MIYAZAWA, M. et al. Análises químicas de tecido vegetal. In: SILVA, F.C. (Org.). Manual de análises químicas de solos, plantas e fertilizantes. Brasília: Embrapa Comunicação para Transferência de Tecnologia, 1999. Cap.4, p.171-224

ORTIGARA, C. et al. Uso do solo e propriedades físico-mecânicas de Latossolo Vermelho. Revista Brasileira de Ciência do Solo, v.38, p.619-626, 2014. Disponível em: <http://www.scielo.br/ scielo.php?script $=$ sci arttext\&pid $=$ S0100-06832014000200026>. Acesso em: 18 out. 2014. doi: 10.1590/S0100-06832014000200026.

REICHERT, J.M. et al. Variabilidade espacial de Planossolo e produtividade de soja em várzea sistematizada: análise geoestatística e análise de regressão. Ciência Rural, v.38, n.4, p.981-988, 2008.

SOUZA, M.A.S. Acúmulo de macronutrientes na soja influenciado pelo cultivo prévio do capim-marandu, correção e compactação do solo. Revista Ciência Agronômica, v.43, n.4, p.611-622, 2012.

SPERA, S.T. et al. Efeito de sistemas de integração lavoura-pecuária sob plantio direto em alguns atributos físicos do solo. Revista Brasileira de Ciências Agrárias, v.7, n.3, p.388-393, 2012. Disponível em: $<$ http://www.redalyc.org/articulo.oa?id=119024529003>. Acesso em: 18 out. 2014. doi: 10.5039/agraria.v7i3a1227.

TAYLOR, H.M. et al. Soil strength root penetration relations for medium to coarse textured soil materials. Soil Science, v.102, n.1, p.18-22, 1966.

TEDESCO, M.J. et al. Análise de solo, plantas e outros minerais. Porto Alegre: UFRGS, Departamento de Solos, Faculdade de Agronomia, 1995. 174p.

Ciência Rural, v.46, n.3, mar, 2016. 